\section{Original Article}

Humanities \&

Forensic Medicine

Check for updates

\title{
Changes in Clinical and Legal Autopsy Rates in Korea from 2001 to 2015
}

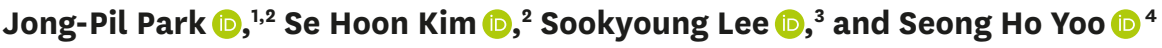 \\ 'Department of Forensic Medicine, Yonsei University College of Medicine, Seoul, Korea \\ ${ }^{2}$ Department of Pathology, Yonsei University College of Medicine, Seoul, Korea \\ ${ }^{3}$ Medical Examiner's Office, National Forensic Service, Wonju, Korea \\ ${ }^{4}$ Institute of Forensic Medicine and Department of Forensic Medicine, Seoul National University College of \\ Medicine, Seoul, Korea
}

Received: Jul 2, 2019

Accepted: Oct 7, 2019

Address for Correspondence:

orrespondence to

Seong Ho Yoo, MD

Institute of Forensic Medicine and Department

of Forensic Medicine, Seoul National University

College of Medicine, 103 Daehak-ro,

Jongno-gu, Seoul 03080, Korea.

E-mail:yoosh@snu.ac.kr

C 2019 The Korean Academy of Medical

Sciences.

This is an Open Access article distributed under the terms of the Creative Commons Attribution Non-Commercial License (https:// creativecommons.org/licenses/by-nc/4.0/) which permits unrestricted non-commercial use, distribution, and reproduction in any medium, provided the original work is properly cited.

ORCID iDs

Jong-Pil Park iD

https://orcid.org/0000-0002-6525-3012 Se Hoon Kim (D)

https://orcid.org/0000-0001-7516-7372

Sookyoung Lee (iD)

https://orcid.org/0000-0002-8939-9526

Seong Ho Yoo (iD)

https://orcid.org/0000-0001-5294-0596

Disclosure

The authors have no potential conflicts of interest to disclose.

\section{ABSTRACT}

Background: The autopsy is the medical examination of a deceased person that mainly provides information on the cause and manner of death. Two types are conducted in Korea: clinical and legal, depending on its purpose. Despite this procedure's importance, autopsy rates have been decreasing worldwide. The aim of this study was to determine the nationwide autopsy rate in Korea and compare it with that in other countries.

Methods: We collected data of autopsies performed between 2001 and 2015 by searching previously published literature on autopsy statistics and by requesting data from the relevant institutions. We calculated the autopsy rate by using mortality data from Statistics Korea; furthermore, we investigated the type of autopsy performed by institution as well as by geographical region.

Results: The total autopsy rate in Korea increased from $2.16 \%$ in 2001 to $2.60 \%$ in 2015. In terms of autopsy types, however, clinical autopsy rates decreased from $0.17 \%$ in 2001 to $0.03 \%$ in 2015 , while legal autopsy rates increased from $1.99 \%$ to $2.57 \%$ during the same period. Moreover, the clinical autopsy rate tended to decrease throughout the period, while the legal autopsy rate fluctuated between 2001 and 2010 but steadily increased thereafter. Conclusion: The autopsy rate in Korea is lower compared to that of the advanced countries. These findings implicate the need for nationwide policy to promote both clinical and legal autopsy, which remain crucial parts of medical science and public health.

Keywords: Autopsy; Forensic Pathology; Korea

\section{INTRODUCTION}

An autopsy is performed to investigate the cause of death via dissection of the deceased's body, and has been the foundation of medical education for a long time. An autopsy can either be clinical or legal based on the reason it is performed. A clinical autopsy is performed when it is necessary to identify the cause of death for medical purposes, mainly for patients who were undergoing treatment at a hospital, whereas a legal autopsy is usually conducted to determine the cause and manner of death according to judicial or administrative directives for persons who experienced unnatural deaths. 


\section{Author Contributions}

Conceptualization: Park JP, Kim SH, Yoo SH Data curation: Park JP, Lee S. Formal analysis: Park JP. Investigation: Park JP, Kim SH, Lee S, Yoo SH. Methodology: Park JP, Kim SH, Lee S, Yoo SH. Software: Park JP. Validation: Lee S. Writing - original draft: Park JP. Writing review \& editing: Kim SH, Lee S, Yoo SH.
Data regarding autopsies within a society not only provide basic information about death statistics per se, but is also important for helping to establish health policy for promoting public health. In Korea, clinical autopsies are mainly performed in the pathology departments of university hospitals at the request of the clinical branches, while legal autopsies are performed at the National Forensic Service (NFS) and at forensic medicine departments of universities upon the request of investigative agencies such as the police. Because autopsies are performed by various institutions, nationwide data regarding this procedure are not managed in an integrated manner, and statistical studies of autopsies are insufficient. In fact, no statistical studies of clinical autopsies have been conducted to date. The first record of legal autopsy data was published by the NFS in 1969, 1 and various statistics have been reported occasionally by specific institutions or regions since. Starting in the late 2000s, the NFS began publishing autopsy statistics annually. Nevertheless, none of these data encompass the entire range of legal autopsies performed in Korea. Therefore, we performed this study to investigate both clinical and legal autopsies nationwide and provide accurate statistics on both.

\section{METHODS}

Data on clinical and legal autopsies performed in Korea between 2001 and 2015 were collected as described below.

\section{Survey for clinical autopsy data}

Clinical autopsy data were retrieved from the Korean Society of Pathologists publications, 'The History of the Korean Society of Pathologists.'2,3 These publications include data on the number of autopsies conducted per hospital; we only used data from university hospitals for our analysis. While we could obtain the records of the autopsies conducted at non-university hospitals, such records were excluded from our analysis because the number of autopsies was small, the number of cases per year was difficult to confirm, and the reliability of the data was unclear. In certain hospitals, autopsies described in the publication were confirmed to be under the 'legal' category, and were therefore excluded from the clinical autopsy analyses. Moreover, data from some hospitals were missing; therefore, we requested this information from these institutions directly. Lastly, data from one hospital were excluded from the analysis because the number of autopsies per year could not be confirmed and the data could not be requested owing to the hospital's closure.

\section{Survey for legal autopsy data}

In Korea, legal autopsies are mainly performed by the NFS or the forensic medicine department of a medical college at the request of the Police Agency, Coast Guard, or Correctional Service. Rarely, the Criminal Investigation Command in the Ministry of National Defense performs an autopsy in case of the death of a military service member. Although the NFS played a central role in autopsy directives in the early 2000s, several private institutions in the region were independently responsible for autopsies as well. Since that time, however, the role of the NFS has expanded, and all legal autopsies (including those in the private sector) are now performed under the supervision of the NFS. While the NFS has taken charge of autopsies in most areas, some locations such as Jeju Island and Ulsan remain under the control of the private sector. Considering this background, we surveyed the institutions that were responsible for the autopsies by region, and directly asked them to provide information on the number of autopsies performed per year. 
In the Seoul/Incheon/Gyeonggi, Gangwon, Daejeon/Chungnam/Chungbuk, and Gwangju/ Jeonnam/Jeonbuk areas, most autopsies were performed by the NFS. However, until the early 2000s, some autopsies were handled directly by university hospitals in the area. In the Daegu/Gyeongbuk area, Kyungpook National University was mainly responsible for the Daegu area while the NFS was responsible for the Gyeongbuk area. Since 2014, the NFS has been responsible for most of the autopsies in this area. In the Busan/Ulsan/Gyeongnam area, autopsies were performed by the NFS and Busan Medico-Legal Committee (a civilian organization) until the early 2000s. From mid-2000 to 2012, the autopsies were conducted at the Pusan National University Hospital, the Busan Medico-Legal Committee, private forensic medicine clinics, and local hospitals. From 2012 onwards, the NFS was responsible for most autopsy cases, although in Ulsan, the procedures are mainly handled by private forensic medicine clinics. In the Jeju area, most autopsies were performed at Jeju National University while some were handled by the NFS. In the case of deaths occurring in the army (regardless of the area), the Criminal Investigation Command in the Ministry of National Defense in charge of the autopsy.

Because of this situation, we requested data from each institute and collected the number of autopsies performed per year based on the annual NFS reports. ${ }^{4-18}$ However, data from the Busan Medico-Legal Committee, which supervised autopsies from the Pusan area until the mid-2000s, as well as data from the Jinju area, could not be collected.

\section{Calculation and analysis of autopsy rates}

The autopsy rates were calculated using the following formulae:

Total autopsy rate $=$ number of total autopsies/number of total deaths

Clinical autopsy rate $1=$ number of clinical autopsies/number of total deaths

Clinical autopsy rate 2 = number of clinical autopsies/number of in-hospital deaths

Legal autopsy rate $1=$ number of legal autopsies/number of total deaths

Legal autopsy rate 2 = number of legal autopsies/number of unusual deaths

The numbers of total and in-hospital deaths were obtained from Statistics Korea. ${ }^{19}$ The number of unusual deaths (defined as a sudden death of unknown cause) was determined as the sum of the number of unnatural deaths and the number of deaths whose causes were unknown at the time of the body's discovery but were ultimately deemed natural. However, as this number could not be determined from the existing data, we counted the number of issued postmortem examination certificates available from Statistics Korea to use for our statistical analysis, rather than the number of unusual deaths.

Clinical autopsies have become more prevalent in certain hospitals over time, and their proportions among all such autopsies were examined. Moreover, the proportions of legal autopsies performed overall and regionally that were under the control of the NFS were analyzed.

\section{Ethics statement}

The study was confirmed as a research activity qualifies as non-human participant by the Institutional Review Board of Seoul National University Hospital (No. 2019-004). All data were analyzed anonymously. The requirement for informed consent was waived by the board. 
Table 1. The number of deaths, the number of autopsy and the autopsy rate by year

\begin{tabular}{crrrrrrrrrrrrrrrr}
\hline Variables & \multicolumn{1}{c}{ Year } \\
\cline { 2 - 10 } & 2001 & 2002 & 2003 & 2004 & 2005 & 2006 & 2007 & 2008 & 2009 & 2010 & 2011 & 2012 & 2013 & 2014 & 2015 \\
\hline Total deaths & 243,813 & 247,524 & 246,463 & 246,220 & 245,874 & 244,162 & 246,482 & 246,113 & 246,942 & 255,405 & 257,396 & 267,221 & 266,257 & 267,692 & 275,895 \\
In-hospital deaths & 96,994 & 107,425 & 110,906 & 114,593 & 122,298 & 133,420 & 147,835 & 156,853 & 162,602 & 172,573 & 176,324 & 187,253 & 190,466 & 195,802 & 205,914 \\
Unusual deaths & 57,869 & 63,531 & 68,753 & 75,718 & 78,137 & 75,145 & 71,128 & 68,146 & 68,421 & 70,514 & 72,250 & 72,253 & 70,300 & 67,919 & 67,893 \\
Total autopsy & 5,270 & 5,829 & 6,328 & 5,686 & 4,859 & 5,104 & 4,948 & 5,297 & 6,013 & 4,827 & 5,125 & 6,090 & 6,079 & 6,707 & 7,180 \\
Clinical autopsy & 420 & 389 & 338 & 303 & 163 & 271 & 312 & 326 & 284 & 229 & 186 & 238 & 164 & 120 & 88 \\
Legal autopsy & 4,850 & 5,440 & 5,990 & 5,383 & 4,696 & 4,833 & 4,636 & 4,971 & 5,729 & 4,598 & 4,939 & 5,852 & 5,915 & 6,587 & 7,092 \\
Total autopsy rate, \% & 2.16 & 2.35 & 2.57 & 2.31 & 1.98 & 2.09 & 2.01 & 2.15 & 2.43 & 1.89 & 1.99 & 2.28 & 2.28 & 2.51 & 2.60 \\
Clinical autopsy rate 1 & 0.17 & 0.16 & 0.14 & 0.12 & 0.07 & 0.11 & 0.13 & 0.13 & 0.12 & 0.09 & 0.07 & 0.09 & 0.06 & 0.04 & 0.04 \\
Clinical autopsy rate 2 & 0.43 & 0.36 & 0.30 & 0.26 & 0.13 & 0.20 & 0.21 & 0.21 & 0.17 & 0.13 & 0.11 & 0.13 & 0.09 & 0.06 & 0.04 \\
Legal autopsy rate 1 & 1.99 & 2.20 & 2.43 & 2.19 & 1.91 & 1.98 & 1.88 & 2.02 & 2.32 & 1.80 & 1.92 & 2.19 & 2.22 & 2.46 & 2.57 \\
Legal autopsy rate 2 & 8.38 & 8.56 & 8.71 & 7.11 & 6.01 & 6.43 & 6.52 & 7.29 & 8.37 & 6.52 & 6.84 & 8.10 & 8.41 & 9.70 & 10.45 \\
\hline
\end{tabular}

\section{RESULTS}

Table 1 shows the number of deaths, the number of autopsies, and the autopsy rate by year. The number of total deaths were 243,813 in 2001 and 275,895 in 2015; although some years had lower numbers than preceding ones, the overall trend was of an increase. The number of in-hospital deaths increased from 96,994 in 2001 to 205,914 in 2015, rising steadily during the study period. The number of unusual deaths increased from 57,869 in 2001 to 67,893 in 2015; however, this number fluctuated annually during the study period.

The number of total autopsies were 5,270 in 2001 and 7,180 in 2015; again, while the numbers declined in some years, there was an overall increasing trend. The number of clinical autopsies exhibited an overall decreasing trend from 420 in 2001 to 88 in 2015, although some years witnessed an increase. The number of legal autopsies increased from 4,850 in 2001 to 7,092 in 2015; while numbers fluctuated between 2001 to 2010, they increased annually between 2010 and 2015 .

The total autopsy rate increased from $2.16 \%$ in 2001 to $2.60 \%$ in 2015 , with continuous fluctuations during the study period. The clinical autopsy rate 1 decreased from $0.17 \%$ in 2001 to $0.03 \%$ in 2015 , while the clinical autopsy rate 2 decreased from $0.43 \%$ in 2001 to

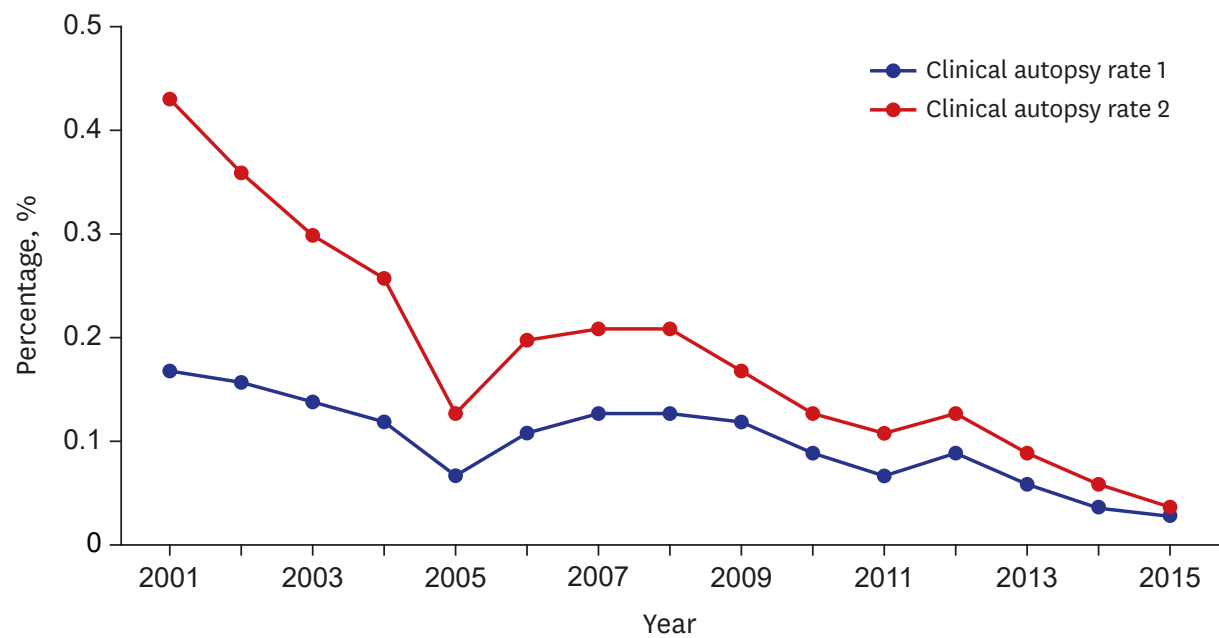

Fig. 1. Clinical autopsy rates (\%) in Korea, 2001-2015. Clinical autopsy rate $1=$ Number of clinical autopsies/ Number of total deaths; Clinical autopsy rate 2 = Number of clinical autopsies/Number of in-hospital deaths. 
Table 2. The proportion of leading hospitals among clinical autopsy

\begin{tabular}{|c|c|c|c|c|c|c|c|c|c|c|c|c|c|c|c|}
\hline \multirow[t]{2}{*}{ Variables } & \multicolumn{15}{|c|}{ Year } \\
\hline & 2001 & 2002 & 2003 & 2004 & 2005 & 2006 & 2007 & 2008 & 2009 & 2010 & 2011 & 2012 & 2013 & 2014 & 2015 \\
\hline Top 2 hospital (\%) & $\begin{array}{c}127 \\
(30.2)\end{array}$ & $\begin{array}{c}158 \\
(40.6)\end{array}$ & $\begin{array}{c}145 \\
(42.9)\end{array}$ & $\begin{array}{c}132 \\
(43.6)\end{array}$ & $\begin{array}{c}94 \\
(57.7)\end{array}$ & $\begin{array}{c}198 \\
(73.1)\end{array}$ & $\begin{array}{c}246 \\
(78.8)\end{array}$ & $\begin{array}{c}241 \\
(73.9)\end{array}$ & $\begin{array}{c}209 \\
(73.6)\end{array}$ & $\begin{array}{c}187 \\
(81.7)\end{array}$ & $\begin{array}{c}159 \\
(85.5)\end{array}$ & $\begin{array}{c}192 \\
(80.7)\end{array}$ & $\begin{array}{c}123 \\
(75.0)\end{array}$ & $\begin{array}{c}81 \\
(67.5)\end{array}$ & $\begin{array}{c}74 \\
(84.1)\end{array}$ \\
\hline Top 5 hospital (\%) & $\begin{array}{c}305 \\
(72.6)\end{array}$ & $\begin{array}{c}294 \\
(75.6)\end{array}$ & $\begin{array}{c}264 \\
(78.1)\end{array}$ & $\begin{array}{c}231 \\
(76.2)\end{array}$ & $\begin{array}{c}111 \\
(68.1)\end{array}$ & $\begin{array}{c}217 \\
(80.1)\end{array}$ & $\begin{array}{c}263 \\
(84.3)\end{array}$ & $\begin{array}{c}282 \\
(86.5)\end{array}$ & $\begin{array}{c}251 \\
(88.4)\end{array}$ & $\begin{array}{c}204 \\
(89.1)\end{array}$ & $\begin{array}{c}166 \\
(89.2)\end{array}$ & $\begin{array}{c}205 \\
(86.1)\end{array}$ & $\begin{array}{c}139 \\
(84.8)\end{array}$ & $\begin{array}{c}84 \\
(70.0)\end{array}$ & $\begin{array}{c}78 \\
(88.6)\end{array}$ \\
\hline Total clinical autopsy & 420 & 389 & 338 & 303 & 163 & 271 & 312 & 326 & 284 & 229 & 186 & 238 & 164 & 120 & 88 \\
\hline
\end{tabular}

$0.04 \%$ in 2015. During the study period, the clinical autopsy rates 1 and 2 increased annually but decreased overall (Fig. 1). The legal autopsy rate 1 increased from $1.99 \%$ in 2001 to $2.57 \%$ in 2015 , while the legal autopsy rate 2 increased from $8.38 \%$ to $10.45 \%$ during the same period. Both the legal autopsy rates 1 and 2 rose and fell between 2001 and 2010, but maintained a study increase afterwards (Fig. 2).

The proportions of clinical autopsies performed at the top 5 highest autopsy-performing hospitals increased from $72.6 \%$ in 2001 to $88.6 \%$ in 2015 ; the proportions of autopsies

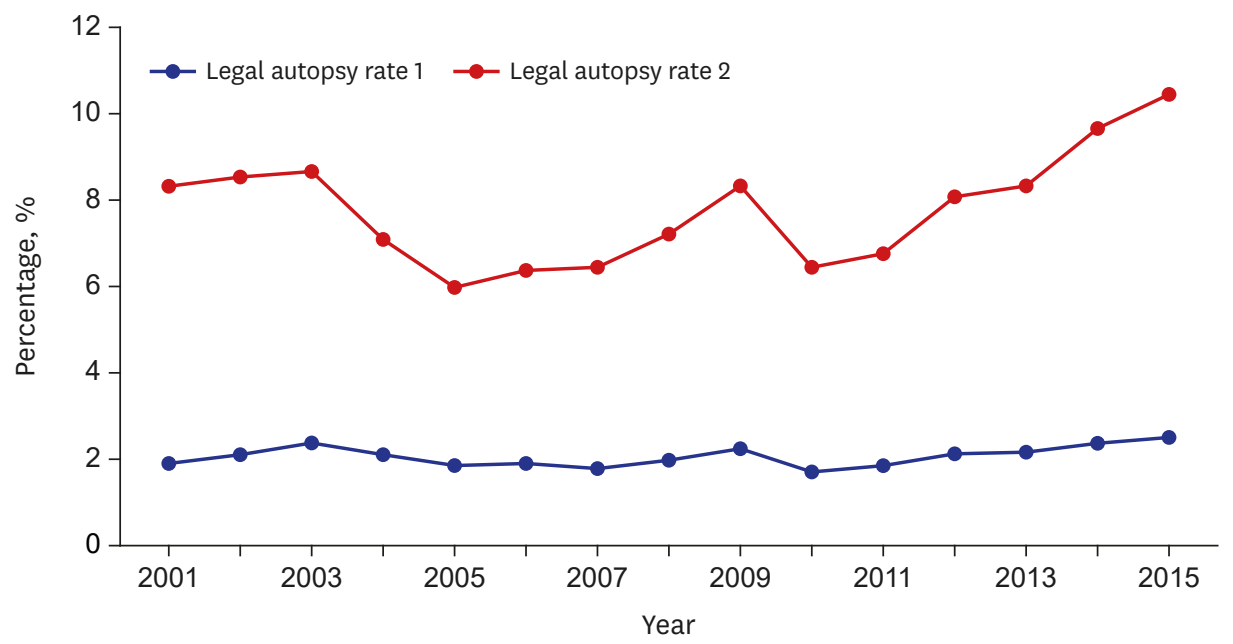

Fig. 2. Legal autopsy rates (\%) in Korea, 2001-2015. Legal autopsy rate $1=$ Number of legal autopsies/Number of total deaths; Legal autopsy rate 2 = Number of legal autopsies/Number of unusual deaths.

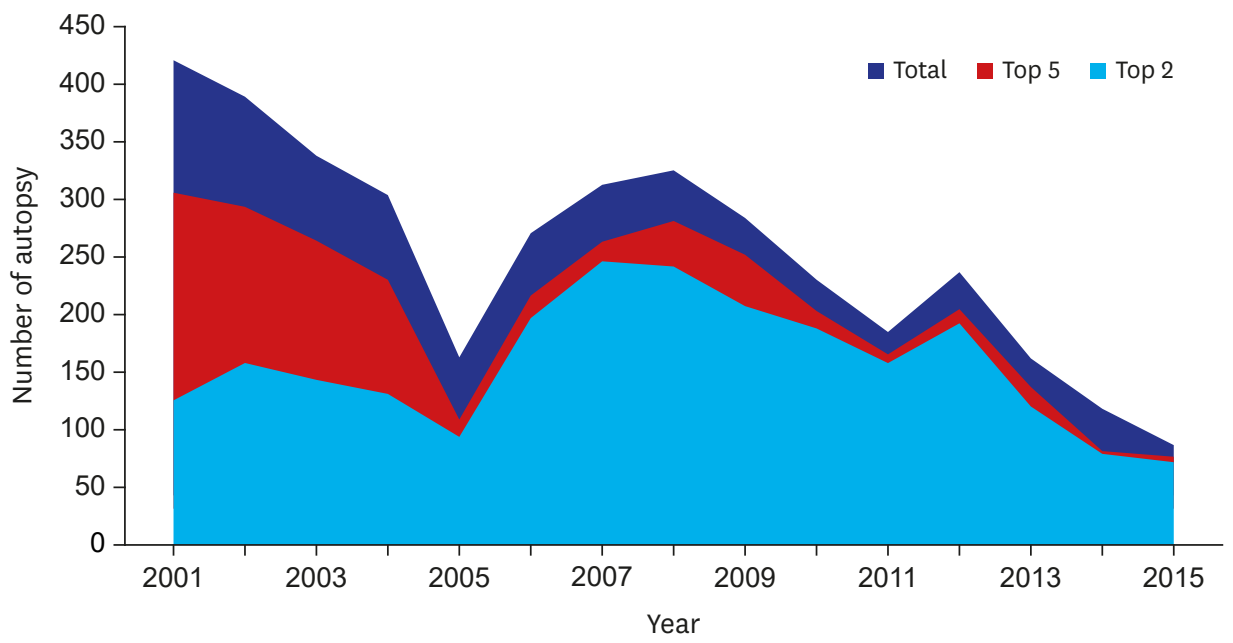

Fig. 3. Changes in the numbers of total clinical autopsies and their proportions at leading hospitals in Korea, 2001-2015. 
Table 3. The porportion of each institutions among legal autopsy

\begin{tabular}{|c|c|c|c|c|c|c|c|c|c|c|c|c|c|c|c|}
\hline \multirow[t]{2}{*}{ Organization } & \multicolumn{15}{|c|}{ Year } \\
\hline & 2001 & 2002 & 2003 & 2004 & 2005 & 2006 & 2007 & 2008 & 2009 & 2010 & 2011 & 2012 & 2013 & 2014 & 2015 \\
\hline NFS (\%) & $\begin{array}{l}4,339 \\
(89.5)\end{array}$ & $\begin{array}{l}4,882 \\
(89.7)\end{array}$ & $\begin{array}{l}5,406 \\
(90.3)\end{array}$ & $\begin{array}{l}4,897 \\
(91.0)\end{array}$ & $\begin{array}{l}4,128 \\
(87.9)\end{array}$ & $\begin{array}{c}3,877 \\
(80.2)\end{array}$ & $\begin{array}{c}3,576 \\
(77.1)\end{array}$ & $\begin{array}{l}3,958 \\
(79.6)\end{array}$ & $\begin{array}{c}4,578 \\
(79.9)\end{array}$ & $\begin{array}{c}3,543 \\
(77.1)\end{array}$ & $\begin{array}{l}3,834 \\
(77.6)\end{array}$ & $\begin{array}{l}5,150 \\
(88.0)\end{array}$ & $\begin{array}{c}5,251 \\
(88.8)\end{array}$ & $\begin{array}{c}6,172 \\
(93.7)\end{array}$ & $\begin{array}{l}6,789 \\
(95.7)\end{array}$ \\
\hline $\mathrm{CIC}(\%)$ & $\begin{array}{c}51 \\
(1.1)\end{array}$ & $\begin{array}{c}69 \\
(1.3)\end{array}$ & $\begin{array}{c}68 \\
(1.1)\end{array}$ & $\begin{array}{c}48 \\
(0.9)\end{array}$ & $\begin{array}{c}61 \\
(1.3)\end{array}$ & $\begin{array}{c}77 \\
(1.6)\end{array}$ & $\begin{array}{c}81 \\
(1.7)\end{array}$ & $\begin{array}{c}56 \\
(1.1)\end{array}$ & $\begin{array}{c}74 \\
(1.3)\end{array}$ & $\begin{array}{c}60 \\
(1.3)\end{array}$ & $\begin{array}{c}70 \\
(1.4)\end{array}$ & $\begin{array}{c}57 \\
(1.0)\end{array}$ & $\begin{array}{c}54 \\
(0.9)\end{array}$ & $\begin{array}{c}51 \\
(0.8)\end{array}$ & $\begin{array}{c}37 \\
(0.5)\end{array}$ \\
\hline Private sectors (\%) & $\begin{array}{c}460 \\
(9.5)\end{array}$ & $\begin{array}{l}489 \\
(9.1)\end{array}$ & $\begin{array}{c}516 \\
(8.6)\end{array}$ & $\begin{array}{l}438 \\
(8.1)\end{array}$ & $\begin{array}{c}507 \\
(10.8)\end{array}$ & $\begin{array}{c}879 \\
(18.2)\end{array}$ & $\begin{array}{c}979 \\
(21.1)\end{array}$ & $\begin{array}{c}957 \\
(19.3)\end{array}$ & $\begin{array}{l}1,077 \\
(18.8)\end{array}$ & $\begin{array}{c}995 \\
(21.6)\end{array}$ & $\begin{array}{l}1,035 \\
(21.0)\end{array}$ & $\begin{array}{c}645 \\
(11.0)\end{array}$ & $\begin{array}{c}610 \\
(10.3)\end{array}$ & $\begin{array}{c}364 \\
(5.5)\end{array}$ & $\begin{array}{l}266 \\
(3.8)\end{array}$ \\
\hline Total legal autopsy & 4,850 & 5,440 & 5,990 & 5,383 & 4,696 & 4,833 & 4,636 & 4,971 & 5,729 & 4,598 & 4,939 & 5,852 & 5,915 & 6,587 & 7,092 \\
\hline
\end{tabular}

NFS $=$ National Forensic Service, $\mathrm{CIC}=$ Criminal Investigation Command.

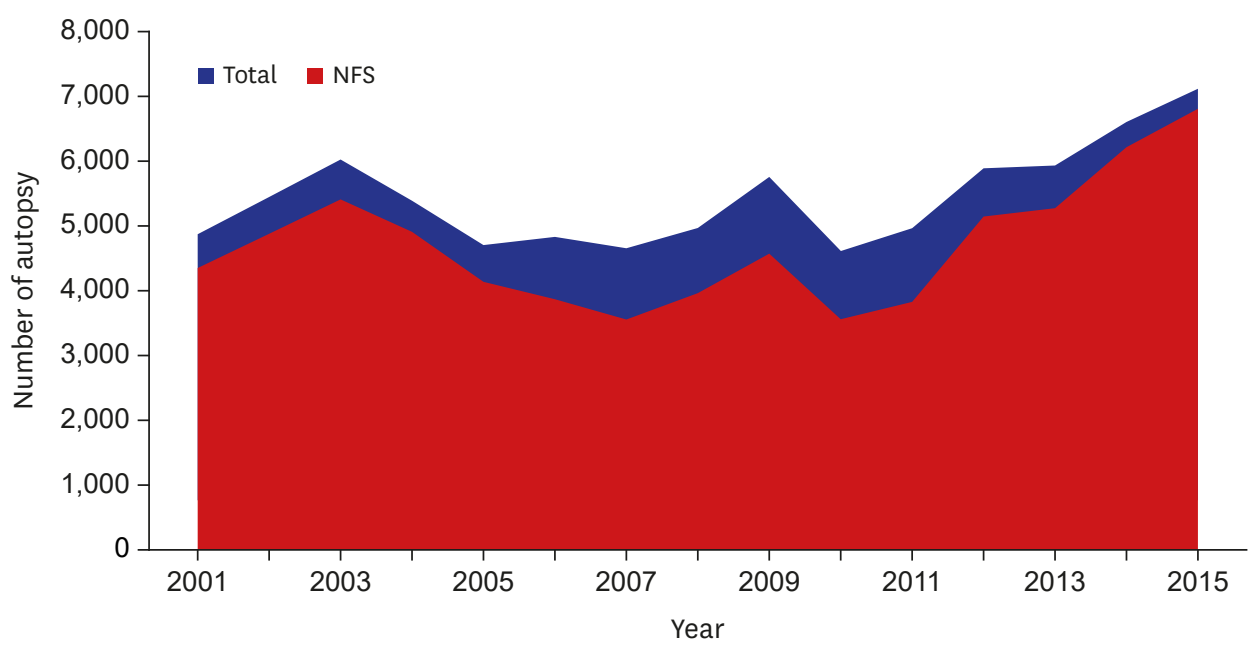

Fig. 4. Changes of the numbers of total legal autopsies and their proportions as performed under the control of the NFS of Korea, 2001-2015.

NFS $=$ National Forensic Service.

performed at the top 2 hospitals increased from $30.2 \%$ in 2001 to $84.1 \%$ in 2015 . While these proportions rose and fell annually during the study period, clinical autopsies tended to be more prevalent at particular institutions (Table 2 and Fig. 3).

The proportions of legal autopsies that were under the control of the NFS increased from $89.5 \%$ in 2001 to $95.7 \%$ in 2015; these proportions rose and fell between 2001 and 2010, but increased annually thereafter (Table 3 and Fig. 4). The number of legal autopsies by region as well as the autopsies performed under the control of the NFS versus the private sector are shown in Table 4.

\section{DISCUSSION}

In this study, we investigated the statuses and rates of autopsies across Korea. In previously published studies regarding autopsy statistics in other countries, research was conducted based on data obtained from public authorities. In Korea, there is no such national registration system; therefore, some data were obtained through the process of direct inquiries to the individual institutions that conducted the autopsies. The Korean National Police Agency and the Korea Coast Guard informed us that they could not provide complete data since no autopsy statistics were collected and because records before the mid-2000s were not computerized. With respect to legal autopsies, however, most are currently performed under the control of the NFS, and the range of its control is gradually expanding. 
Table 4. The number of legal autopsy by region

\begin{tabular}{|c|c|c|c|c|c|c|c|c|c|c|c|c|c|c|c|c|}
\hline Region & Organization & 2001 & 2002 & 2003 & 2004 & 2005 & 2006 & 2007 & 2008 & 2009 & 2010 & 2011 & 2012 & 2013 & 2014 & 2015 \\
\hline \multirow{3}{*}{$\begin{array}{l}\text { Seoul/ } \\
\text { Incheon/ } \\
\text { Gyeonggi }\end{array}$} & NFS & 2,575 & 2,913 & 3,030 & 2,937 & 2,436 & 2,418 & 2,258 & 2,455 & 2,936 & 2,072 & 2,379 & 3,147 & 3,105 & 3,393 & 3,845 \\
\hline & Private sectors & 17 & 7 & 3 & 5 & 1 & 0 & 0 & 0 & 0 & 0 & 0 & 0 & 0 & 0 & 0 \\
\hline & Total & 2,592 & 2,920 & 3,033 & 2,942 & 2,437 & 2,418 & 2,258 & 2,455 & 2,936 & 2,072 & 2,379 & 3,147 & 3,105 & 3,393 & 3,845 \\
\hline \multirow[t]{3}{*}{ Gangwon } & NFS & 119 & 116 & 162 & 133 & 117 & 167 & 194 & 174 & 217 & 201 & 154 & 179 & 210 & 229 & 335 \\
\hline & Private sectors & 5 & 2 & 0 & 0 & 0 & 0 & 0 & 0 & 0 & 0 & 0 & 0 & 0 & 0 & 0 \\
\hline & Total & 124 & 118 & 162 & 133 & 117 & 167 & 194 & 174 & 217 & 201 & 154 & 179 & 210 & 229 & 335 \\
\hline \multirow{3}{*}{$\begin{array}{l}\text { Daejeon/ } \\
\text { Chungnam/ } \\
\text { Chungbuk }\end{array}$} & NFS & 488 & 530 & 821 & 636 & 599 & 558 & 498 & 612 & 661 & 611 & 549 & 524 & 583 & 757 & 756 \\
\hline & Private sectors & 9 & 12 & 3 & 0 & 0 & 0 & 0 & 0 & 0 & 0 & 0 & 0 & 0 & 0 & 0 \\
\hline & Total & 497 & 542 & 824 & 636 & 599 & 558 & 498 & 612 & 661 & 611 & 549 & 524 & 583 & 757 & 756 \\
\hline \multirow{3}{*}{$\begin{array}{l}\text { Gwangju/ } \\
\text { Jeonnam/ } \\
\text { Jeonbuk }\end{array}$} & NFS & 664 & 653 & 536 & 718 & 577 & 522 & 509 & 571 & 567 & 495 & 536 & 560 & 567 & 708 & 664 \\
\hline & Private sectors & 21 & 20 & 14 & 27 & 25 & 20 & 0 & 0 & 0 & 0 & 0 & 0 & 0 & 0 & 0 \\
\hline & Total & 685 & 673 & 550 & 745 & 602 & 542 & 509 & 571 & 567 & 495 & 536 & 560 & 567 & 708 & 664 \\
\hline \multirow{3}{*}{$\begin{array}{l}\text { Daegu/ } \\
\text { Gyeongbuk }\end{array}$} & NFS & 65 & 112 & 341 & 127 & 167 & 94 & 105 & 139 & 142 & 150 & 190 & 226 & 253 & 420 & 520 \\
\hline & Private sectors & 304 & 323 & 342 & 314 & 313 & 294 & 251 & 208 & 220 & 220 & 218 & 171 & 184 & 76 & 32 \\
\hline & Total & 369 & 435 & 683 & 441 & 480 & 388 & 356 & 347 & 362 & 370 & 408 & 397 & 437 & 496 & 552 \\
\hline \multirow{3}{*}{$\begin{array}{l}\text { Busan/ } \\
\text { Ulsan/ } \\
\text { Gyeongnam }\end{array}$} & NFS & 426 & 558 & 516 & 342 & 224 & 114 & 8 & 7 & 39 & 10 & 23 & 514 & 533 & 658 & 668 \\
\hline & Private sectors & 23 & 33 & 35 & 10 & 75 & 489 & 653 & 677 & 776 & 680 & 725 & 339 & 297 & 196 & 91 \\
\hline & Total & 449 & 591 & 551 & 352 & 299 & 603 & 661 & 684 & 815 & 690 & 748 & 853 & 830 & 854 & 759 \\
\hline \multirow[t]{3}{*}{ Jeju } & NFS & 2 & 0 & 0 & 4 & 1 & 3 & 4 & 0 & 15 & 4 & 3 & 0 & 0 & 7 & 1 \\
\hline & Private sectors & 81 & 92 & 119 & 82 & 93 & 76 & 75 & 72 & 81 & 95 & 92 & 135 & 129 & 92 & 143 \\
\hline & Total & 83 & 92 & 119 & 86 & 94 & 79 & 79 & 72 & 96 & 99 & 95 & 135 & 129 & 99 & 144 \\
\hline
\end{tabular}

NFS $=$ National Forensic Service

As more such institutional autopsy data are available to the NFS, a clearer picture of the status of nationwide legal autopsies will be attainable.

As mentioned above, the main source for clinical autopsy data was 'The history of the Korean Society of Pathologists.' These volumes are published every 10 years and contain data on the number of autopsies conducted by each institution annually. However, because these publications were not originally produced for the purposes of investigating clinical autopsy statistics, there were limitations to their use. For example, the number of autopsies performed in 2005 was significantly lower than that of the previous year, but increased again in the following year. It is unclear whether this fluctuation was caused by fewer autopsies performed that year or by missing data. Data compiled between 1996 and 2005 were published at the end of 2006, and those compiled between 2006 and 2015 were published at the end of 2016. As such, lapses in estimates are possible because some institutions were missing data in 2005/2015 or provided data only until mid-2005/2015 (i.e., the data cutoff years before compilation for publication).

It is necessary to confirm the number of unusual deaths in order to obtain the actual legal autopsy rate. Unusual deaths are sudden and have no known cause, and encompass not only unnatural deaths but also those that turn out to be natural upon further investigation. The reason for this definition is that the cause of death sometimes can only be ascertained via postmortem examination (including autopsy). However, it was not always possible to obtain the data necessary to make such a determination. The unusual death statistics provided by the Korean National Police Agency and the Korea Coast Guard, which were used mainly for legal autopsy research, were available only for unnatural deaths, and did not meet the criteria defined in our study. Cases in which the manners of deaths were determined to be natural after autopsy accounted for a high proportion of 'unusual' deaths; these were excluded from the statistical data of the Korean National Police Agency and Korea Coast Guard. To address the lack of these data, the number of issued postmortem examination certificates was used instead of the number of unusual deaths, although certificates also have some limitations. 
In Korea, it is stipulated that a death certificate should be prepared when a patient who is being treated at a hospital dies of a related illness or an unnatural cause; otherwise, a postmortem examination certificate should be prepared. However, death certificates and postmortem examination certificates are commonly used interchangeably, and there is a tendency to issue death certificates in situations where postmortem examination certificates should be used instead. Furthermore, even if a death certificate is issued, an unusual death should be noted in case of an unnatural death, but these cases could not be included in this study. Therefore, the number of issued postmortem examination certificates (which we used in lieu of the number of unusual deaths) would likely be smaller than the number of actual unusual deaths.

In some situations, the autopsy was performed while the legal autopsy data were not sought; however, the exact number of such instances was unknown, and these cases were excluded from our study (specifically, data of the Busan Medico-Legal Committee and Jinju area). The Busan Medico-Legal Committee provided a statement stating that approximately 100 autopsies were performed annually until the mid-2000s, while Jinju area officials confirmed that autopsies were continuously performed until the late 2000s. Therefore, the number of autopsies reported herein up until the late 2000s is smaller than the actual number; the number of missing autopsies during this period is estimated to be less than 150, and the impact on overall autopsy statistics is not expected to be significant. Despite these limitations, we have collected all the data that are verifiable at the present time, which ought to give our study credence.

It is worth noting that autopsy systems differ between countries when comparing the autopsy rates. However, the autopsy rate in Korea remains lower than those in the United States, Japan, and Europe. In the United States, the total autopsy rate decreased from 19.3\% in 1972 to $8.5 \%$ in 2007; the rate decreased from $16.9 \%$ to $4.3 \%$ in cases of death as a consequence of disease, but increased from $43.6 \%$ to $55.4 \%$ in cases of unnatural death. ${ }^{20}$ In Japan, it was difficult to determine the total and legal autopsy rates, although the number of clinical autopsies decreased from 23,086 in 1974 to 11,473 in 2016,21 and the clinical autopsy rate (i.e., the number of clinical autopsies/number of in-hospital deaths) at university hospitals decreased from 49.2\% in 1981 to $6.8 \%$ in 2012.22 In the United Kingdom, the total autopsy rate decreased from $42.7 \%$ in 1979 to $15.3 \%$ in $2001 ;{ }^{23}$ the clinical autopsy rate (number of clinical autopsies/number of in-hospital deaths) in 2013 was $0.69 \% .{ }^{24}$ The legal autopsy rate (number of legal autopsies/ number of unusual deaths) in England and Wales in 2013 was 41\%.24 In Finland, a country with one of the highest autopsy rates, the clinical autopsy rate (number of clinical autopsies/ number of total deaths) decreased from $18.8 \%$ in 1970 to $8.3 \%$ in 2004, while the legal autopsy rates (number of legal autopsies/number of total deaths) increased from $13.6 \%$ to $23.8 \%$ during the same period. ${ }^{25}$ As the method for calculating the autopsy rate differs between countries, direct comparison is difficult. However, analysis of the autopsy rates reported in several studies revealed declining clinical autopsy rates and slightly increasing legal autopsy rates. ${ }^{26-30}$

According to studies on clinical autopsy of other countries, few physicians request autopsies nowadays, largely owing to advances in radiology and diagnostics; concordantly, the proportions of limited and pediatric clinical autopsies have tended to increase. ${ }^{31-33}$ The decrease in clinical autopsy rate seems to be caused by the decrease in the necessity of clinical autopsy due to the dazzling development of medical care over the past decade including various diagnostic techniques including radiological diagnostic test. In our study, we did not investigate the specifics of clinical autopsies in Korea; however, it can be inferred that the situation in Korea is similar to those of other countries in that clinical autopsies are largely 
restricted to certain major hospitals. Incidentally, brain banking (the collection of brains post-mortem for clinical research) has been increasingly adopted in recent years.

The rate of legal autopsy in Korea has been increasing in recent years, as has the proportion of autopsies performed under the control of the NFS. The increase in the legal autopsy rate is due to a change in social phenomena because forensic medicine is a kind of social medicine. As the large family system has turned into a nuclear family and now the proportion of people living alone has increased, the death of which cause and manner are uncertain because of the limitation of information on the deceased has increased and the legal autopsy rate has increased as a result. This is also owing to the fact that social awareness of the necessity of the legal autopsies has increased, more autopsy orders delivered by investigating agencies are being implemented, and the function of the NFS is expanding. While this trend is encouraging, it is also necessary to regulate the role of the private sector, such as university hospitals, when implementing legal autopsies.

The increase in the legal autopsy is a positive phenomenon, but the decline in the clinical autopsy is expected to have an adverse effect on the legal autopsy over the medium to long term. The university hospital autopsy room, where autopsy is rarely performed, is likely to be diverted to other uses at the convenience of each institution suffering from space shortage. Then the clinical autopsy will be even more shrinking, and the number of pathologists interested in autopsy will decrease. It will also be a stumbling block when trying to expand the judicial sword in conjunction with the university autopsy room, and in the end, it will also be a stumbling block when trying to expand the legal autopsy in conjunction with the university autopsy room. As an alternative to this, it may be necessary to consider ways to supplement the relevant systems so that researchers can gain access to postmortem human tissues for research purposes.

In conclusion, this first study of overall autopsy rates in Korea found that Korea has maintained a lower autopsy rate compared to the developed countries, and clinical autopsies showed the sheer decline while legal autopsies have slightly increased. This finding strongly suggests that a thorough re-consideration for death investigation system in Korea should be made.

\section{ACKNOWLEDGMENTS}

We would like to acknowledge and thank the investigators from all participating institutions: the Criminal Investigation Command in the Ministry of National Defense, Kyungpook National University (SangHan Lee), Jeju National University (Hyun-Wook Kang), Chonnam National University (Jong-Tae Park), Chonbuk National University (Sang Jae Noh), Yonsei University Wonju college of Medicine (Minseob Eom), Pohang Semyeong Christianity Hospital (Jae Won Im), Samsung Seoul Hospital (Jung-Sun Kim), Eui U Park, Kwang Hoon Kim, Gam Rae Jo, Sang Yong Lee, Byeong Woo Min, Ojun Kwon, and Korea Statistics (Seok Min Lee).

\section{REFERENCES}

1. Woo SD. A statistical observation on medico-legal autopsy and inspection in Korea. Yonsei Med J 1969;10(1):71-5.

PUBMED | CROSSREF 
2. Compilation Committee if the History (1996-2005) of Korean Society of Pathologists. The History of the Korean Society of Pathologists 1996-2005. Seoul: Korean Society of Pathologists; 2006.

3. Compilation Committee of the 70-Year History of Korean Society of Pathologists. The History of the Korean Society of Pathologists 2006-2015. Seoul: Korean Society of Pathologists; 2016.

4. National Institute of Scientific Investigation. 2002 Annual Report of the National Institute of Scientific Investigation. Seoul: National Institute of Scientific Investigation; 2002.

5. National Institute of Scientific Investigation. 2003 Annual Report of the National Institute of Scientific Investigation. Seoul: National Institute of Scientific Investigation; 2003.

6. National Institute of Scientific Investigation. 2004 Annual Report of the National Institute of Scientific Investigation. Seoul: National Institute of Scientific Investigation; 2004.

7. National Institute of Scientific Investigation. 2005 Annual Report of the National Institute of Scientific Investigation. Seoul: National Institute of Scientific Investigation; 2005.

8. National Institute of Scientific Investigation. 2006 Annual Report of the National Institute of Scientific Investigation. Seoul: National Institute of Scientific Investigation; 2006.

9. National Institute of Scientific Investigation. 2007 Annual Report of the National Institute of Scientific Investigation. Seoul: National Institute of Scientific Investigation; 2007.

10. National Institute of Scientific Investigation. 2008 Annual Report of the National Institute of Scientific Investigation. Seoul: National Institute of Scientific Investigation; 2008.

11. National Institute of Scientific Investigation. 2009 Annual Report of the National Institute of Scientific Investigation Seoul: National Institute of Scientific Investigation; 2009.

12. National Forensic Service. 2010 Annual Report of The National Forensic Service. Seoul: National Forensic Service; 2010.

13. National Forensic Service. 2011 Annual Report of The National Forensic Service. Seoul: National Forensic Service; 2011.

14. National Forensic Service. 2012 Annual Report of The National Forensic Service. Seoul: National Forensic Service; 2012.

15. National Forensic Service. 2013 Annual Report of The National Forensic Service. Seoul: National Forensic Service; 2013

16. National Forensic Service. 2014 Annual Report of The National Forensic Service. Wonju: National Forensic Service; 2014.

17. National Forensic Service. 2015 Annual Report of The National Forensic Service. Wonju: National Forensic Service; 2015.

18. National Forensic Service. 2016 Annual Report of The National Forensic Service. Wonju: National Forensic Service; 2016.

19. Korean Statistical Information Service. Causes of death statistics. http://kosis. $\mathrm{kr} / \mathrm{eng} /$ statisticsList/statisticsListIndex.do?menuId=M_01_01\&vwcd=MT_ ETITLE\&parmTabId=M_01_01\&statId=1999038\&themaId=\#D11.3. Updated 2019. Accessed June 17, 2019.

20. Hoyert DL. The changing profile of autopsied deaths in the United States, 1972-2007. NCHS Data Brief 2011;(67):1-8. PUBMED

21. The Japanese Society of Pathology. Number of autopsies in Japan. http://pathology.or.jp/kankoubutu/ autopsy-index.html. Updated 2019. Accessed June 17, 2019.

22. Yang X, Bai J, Imai H. Changes in autopsy rate in Japanese university hospitals during the past 34 years. Juntendo Med J 2016;62(3):240-7. CROSSREF

23. Burton JL, Underwood J. Clinical, educational, and epidemiological value of autopsy. Lancet 2007;369(9571):1471-80. PUBMED | CROSSREF

24. Turnbull A, Osborn M, Nicholas N. Hospital autopsy: endangered or extinct? J Clin Pathol 2015;68(8):601-4. PUBMED | CROSSREF

25. Lunetta P, Lounamaa A, Sihvonen S. Surveillance of injury-related deaths: medicolegal autopsy rates and trends in Finland. Inj Prev 2007;13(4):282-4. PUBMED | CROSSREF

26. Blokker BM, Weustink AC, Hunink MGM, Oosterhuis JW. Autopsy rates in the Netherlands: 35 years of decline. PLoS One 2017;12(6):e0178200. PUBMED | CROSSREF 
27. Grassow-Narlik M, Wessolly M, Friemann J. Autopsy rates in Germany. Pathologe 2017;38(5):422-9. PUBMED | CROSSREF

28. Kunz SN, Bergsdóttir P, Jónasson JG. Autopsy rates in Iceland. Scand J Public Health 2019:1403494818820748. PUBMED | CROSSREF

29. Raut A, Andrici J, Severino A, Gill AJ. The death of the hospital autopsy in Australia? The hospital autopsy rate is declining dramatically. Pathology 2016;48(7):645-9. PUBMED | CROSSREF

30. Rodewald AK, Bode P, Cathomas G, Moch H. Clinical autopsies in Switzerland: a status report. Pathologe 2017;38(5):416-21. PUBMED | CROSSREF

31. Turnbull A, Martin J, Osborn M. The death of autopsy? Lancet 2015;386(10009):2141. PUBMED | CROSSREF

32. Levy B. Informatics and autopsy pathology Surg Pathol Clin 2015;8(2):159-74. PUBMED | CROSSREF

33. Fligner CL, Dighe MK. Post-mortem diagnosis: evolving a team approach. Lancet 2013;382(9888):186-8. PUBMED | CROSSREF 